\title{
An Empirical Study on the Relationship Between Advertising Spending, Network Channel and Retail Enterprise Performance
}

\author{
Wei Na \\ Department of Economics, Shanghai University, Shanghai, China
}

\section{Email address:}

weinavip@126.com

\section{To cite this article:}

Wei Na. An Empirical Study on the Relationship Between Advertising Spending, Network Channel and Retail Enterprise Performance. Science Innovation. Vol. 5, No. 2, 2017, pp. 112-116. doi: 10.11648/j.si.20170502.18

Received: March 28, 2017; Accepted: April 17, 2017; Published: April 20, 2017

\begin{abstract}
Theoretical analysis shows that advertising spending, network channel performance is related with the retail enterprise, this article uses the data of listed companies in 2015 retail research retail business advertising spending in China and the relationship between corporate performance and the network channels opened in the retail business performance, the conclusion, found that advertising spending influence on the performance of retail enterprises under the influence of retail enterprise scale, retail enterprise scale is larger, the more advertising spending, retail enterprise performance, the better; Network channels to the opening of the negative influence to the retail business performance, but advertising spending more enterprises open network channels will promote the retail business performance. Retail enterprises should base on their own actual decision-making and should not blindly follow the trend to pay for a large number of advertising expenses and open network channels.
\end{abstract}

Keywords: Retail, Performance, Advertisement Spending, Network Channel

\section{广告支出、网络渠道与零售企业绩效关系的实证研究}

\section{魏娜}

经济学院, 上海大学, 上海, 中国

邮箱

weinavip@126.com

摘要: 理论分析表明, 广告支出、网络渠道与零售企业绩效正相关, 本文使用 2015 年零售业上市公司数据研究中国零 售企业广告支出与企业绩效关系以及网络渠道的开通对零售企业绩效的作用。结论发现, 广告支出对零售企业的绩效 影响受到零售企业规模的影响, 零售企业规模越大, 广告支出越多, 零售企业绩效越好; 网络渠道的开通对零售企业 绩效起负向影响, 但是广告支出多的企业开通网络渠道会促进零售企业绩效。零售企业应根据企业自身实际决策, 不 应该盲目跟风，进行大量广告费用支出与开通网络渠道。

关键词: 零售, 绩效, 广告支出, 网络渠道 


\section{1. 引言}

自 20 世纪70年代以来, 我国零售业发展迅猛, 已经成 为国民经济中的重要组成部分。2015年我国社会消费品零 售总额达 300931 亿元，同比增长 $10.7 \%$ ，较1978年增长了 193倍。但随着零售市场的竞争加剧, 市场绩效逐年下降, 零售业已经成为典型的微利行业。零售商为获取市场份额, 往往采取很多手段, 现实中, 零售企业采用广告实现差异 化, 加强品牌知名度来推广产品, 各大连锁零售巨头纷纷 将广告作为提高经营绩效和企业竞争力的重要手段。但是 大量广告投入是否有真的如零售商们预想的效果, 本文旨 在探讨零售企业的广告支出对其经营绩效的影响。

随着信息技术的进步和网络覆盖范围的扩大, 尤其是 国家对农村地区网络建设的支持力度不断加大, 网络购物 用户规模持续壮大。截至2015年底，全国网民规模达6.9 亿人, 比 2012 年增长 $22 \%$, 互联网普及率从 $42.1 \%$ 提高到 50.3\%。2015年，全国网上零售额达 38773 亿元，同比增长 33. 3\%。随着互联网的发展, 网络电商异军突起, 对实体 零售造成巨大冲击, 众多传统零售企业选择开通网络渠道, 网络渠道的开通是否会对企业绩效产生影响, 这是本文主 要探讨的问题。

\section{2. 文献综述}

广告支出一直在产业组织理论中占有重要地位, 早在 20 世纪70年代就有外国学者

对广告投入所带来的企业绩效进行研究。Comanor, Wi1son（1967）通过对消费品行业的研究, 发现广告投入 可以增大产品差异化程度，建立起进入壁垒，从而对利润 率产生正向影响 [1]。Bhagwat 和DeBruine [2] 以制药业 为样本进行研究, 发现广告支出增加 $1 \%$, 企业销售与收入 就增加 $12.5 \%$ 。Clarke（1976）基于广告与销售量之间的 关系进行研究，发现广告对于影响销售量的时间一般只维 持3到15个月 [3]。Hirschey, Weygandt（1985）[4]以390 家公司作为样本，研究发现公司广告支出与Tobin' $s Q$ 值有显著的正相关性。国内学者杜渏, 㚞文英 (2009) [5] 运用面板协整分析研究得出结论, 广告费用对销售增长有 显著影响, 且以 1.261 个单位的正向程度影响企业的销售 额。许晖, 王宣喻（2013）[6] 以酿酒公司为研究对象, 发现企业的广告投入与销售业绩呈现非线性关系。

马艳艳 [7]使用实证研究了广告支出与企业经济绩效 存在U型关系, 随着企业广告支出的增加, 企业经济绩效 先降低后上升。赵保国、阙人超 [8]通过实证检验广告费 用投入强度与企业绩效之间并不是简单的线性关系，传统 企业广告投入对经营绩效的影响呈现出明显的阶段性特 征。

互联网时代的到来为零售开辟了新的纪元, 传统零售 商纷纷将目光转向网络渠道零售, 借以利用网络资源, 扩 展营销渠道, 扩大市场。McGrath和Ze11 [9]认为通过减少 分销层次, 网络渠道可以使信息流程、谈判流程、数字产 品或服务流程、促销流程变得便利高效, 从而降低企业的 交易成本。网络渠道同时也缩短了供应链的长度, 节省物
质资源的耗费，给企业带来极大的隐含效益。互联网渠道 带给零售商最明显的好处是线上资源和线下资源的互补 效应 [10]。Steinfield等 [11]和姜国政 [10]研究了整合两 种渠道的潜在好处, 这包括增强信任, 减少消费者的风险 和更广泛、更多样的购物选择范围, 并指出企业在设计自 己的分销渠道时, 必须对两者予以同样程度的重视。 Bonner等[13]也指出, 对多重渠道关系的有效管理可以提 高渠道效率, 能对多个细分市场产生吸引力。邵家兵 [14]

（2015）等研究了网络渠道应用对零售商绩效的影响, 结 论是网络渠道的运用是公司在销售额、成本、库存和投资 回报等方面的绩效有了显著的改善。石平,颜波, 石松 [15] 采用实物期权方法分别建立渠道集成策略和渠道更新策 略下公司的价值函数, 分析运营成本的不确定性对网络渠 道开通时机选择的影响。

关于企业绩效的影响因素研究较多, 角度也各异, 涉 及到高管特征 [16]、企业创新 [17]、知识产权保护执法力 度 [18]、供应链整合 [19]、国际化程度 [20]等角度, 研究 方法从理论到实证。

综合上述文献, 可以看出, 广告与网络渠道作为零售 产业组织重要的行为, 过往的研究还未对其交互作用进行 研究, 本文基于中国零售上市企业数据, 实证检验广告支 出、网络渠道与零售企业绩效间的关系。

\section{3. 假设的提出}

根据广告功能, 可以将广告分为信息性广告和说服性 广告。信息性广告会吸引更多的消费者来购买企业产品, 说服性广告则会增强消费者对购买企业产品的忠诚度，从 而提高消费者转向替代产品的心理成本。所以, 在产品质 量、价格以及所有其他方面不变的情况下, 广告可以增加 企业的销售量, 从而增强企业绩效。并且, 广告支出有显 著规模经济特性。这表现在两方面: 一方面, 就某一绝对 水平的广告支出而言, 企业的销售量越大, 平均到每个单 位产品上的广告成本越小; 另一方面, 企业也可能存在生 产上的规模经济, 如果企业的现有规模小于最小有效规模, 则随着广告支出而来的销售量的增大也能降低企业的生 产成本。

通过文献梳理可以发现广告支出对零售企业的销售 额有正向作用, 零售企业的最终目的是为了提高其经济绩 效。广告有助于提高顾客对品牌认知度, 从而形成品牌壁 垒。通过广告建立起来的进入壁垒，使得在位企业可以维 持一定的市场势力, 进而获取垄断利润。潜在竞争对手是 否进入广告密集的行业通常会比较慎重, 因为 “进入” 意 味着要支出更多的广告费克服在位者建立起来的品牌忠 诚度。此外, 大额的广告支出可能会侵蚀企业的超额利润, 这会降低潜在竞争者的激励 [21]。因此, 本文假设:

假设 1：广告支出与企业绩效呈正相关; 企业规模会 影响广告支出与企业绩效的关系, 在大企业里, 二者的关 系会更强。广告支出对企业绩效有正向影响。

根据文献讨论, 可以发现网络渠道为传统零售企业带 来一些潜在利益。它可以通过扩大市场同时利用规模经济 和线上线下渠道的协同效应提高运营效率, 来提高零售商 
的收入。此外, 零售商通过既有的和更灵活的订单、配送、 回收管理可以改进客户服务, 提升顾客粘性。广告支出对 网络渠道开通对企业绩效的影响有调节作用, 零售商通过 广告宣传, 可以扩大其企业影响力, 增强消费者对其品牌 的认知度，实现线上线下渠道的销售能力的提升。但是， 目前开通网络渠道对企业绩效的影响尚未有定论, 因此, 提出如下假设:

假设 2 : 开通网络渠道有助于提升企业绩效, 广告支 出会影响是否开通网络渠道和企业绩效的关系, 但影响方 向不确定。

\section{4. 研究方法}

\section{1. 数据来源}

本研究所采用的数据为 2015 年沪深A股零售业上市公 司数据, 来自WIND数据库。根据WIND行业分类的统计, 到 2015年年底，中国沪深两市中，零售类的上市公司共有79 家, 考虑到数据的可靠性和一致性, 剔除样本中的ST公司 和*ST公司, 剔除同时在B股上市的公司, 最后得到 72 家 上市零售企业进行研究。

其中, 对于 72 家零售企业, 关于是否开通网络渠道的 数据, 是用百度搜索查询并确认了每一个公司的网站, 剔 除了没有网上店铺的公司。对于开通网络渠道的公司, 又 再一次确认了该网站是否正常运行, 是否可以正常为客户 下订单和具有网络支付结算的功能。经过网站调研发现, 许多公司的网站只是展示了简单的营销信息, 实际上没有 销售功能, 这里将这些公司排除在外。72家零售上市公司 中, 37家零售企业开通了可以正常运行的网络渠道, 35 家零售企业并未开通网络渠道。

\section{2. 变量定义}

\section{2. 1. 企业绩效的度量}

将零售企业的经济绩效定义为本文的因变量, 采用总 资产报酬率（ROA）表示企业的经济绩效，总资产报酬率 衡量企业总资产获利能力, 总资产报酬率=利润总额/总资 产平均余额 $* 100 \%$ 。

\section{2. 2. 解释变量}

因上市公司年报未直接披露广告支出，所以将支付的 其他与经营有关的现金流量与销售额的比值定义为广告 强度 [22]。关于网络渠道的研究在过往的文献中均是采用 虚拟变量, 所以, 本文也采用此方法, 将是否开通网络渠 道表达为虚拟变量, 若开通, 则取值为 1 否则为 0 。

\section{2. 3. 控制变量}

先前的大量研究表明, 规模和资本结构会影响企业绩 效。为控制在企业层面的规模经济, 本文把规模作为控制 变量包含在回归分析中。资本结构也会影响企业绩效, 这 里使用债务总额/资产总额来衡量资本结构。存货周转率 反映企业存货的周转速度, 衡量企业生产经营各环节中存 货运营效率，还被用来评价企业的经营业绩，反映企业的 绩效 [23]。变量如表1:
表1 文中使用的变量。

\begin{tabular}{lll}
\hline 变量名 & 变量名 & 变量表达式 \\
\hline 因变量 & 总资产报酬率 $(\mathrm{Y})$ & 利润总额/总资产平均余额* $100 \%$ \\
& 广告强度 $(\mathrm{X} 1)$ & 支付的其他与经营有关的现金流/ \\
自变量 & 是否开通网络渠道 & 销售额 \\
& $(\mathrm{X} 2)$ & 亚变量, 开通为 1, 否则为 0 \\
& 企业规模 $(X 3)$ & 资产总额的对数 \\
变量 & 资产负债率 $(X 4)$ & 负债总额/资产总额 \\
& 存货周转率 $(X 5)$ & 主营业务成本/平均存货余额 \\
\hline
\end{tabular}

4. 3. 实证分析

\section{3. 1. 规模效应考察}

本文采用如下模型来估计广告支出与规模和广告支 出的交互作用对绩效的影响:

$Y_{i}=\beta_{0}+\beta_{1} X 1_{i}+\beta_{2} X 2_{i}+\beta_{3} X 3_{i}+\beta_{4} X_{5}+\beta_{5} \mathrm{X} 1_{i} \mathrm{X} 2_{i}+\mu$

其中, $Y_{i}$ 为企业绩效, 用总资产报酬率 (ROA) 衡量, $\mathrm{X} 1$ 为企业规模, 用总资产的自然对数来衡量。X2为广告 强度, $\mathrm{X} 3$ 为资产负债率, $\mathrm{X} 5$ 为存货周转率, $\mu$ 为随机扰动 项。

多元回归分析结果见表 2:

表2 回归结果。

\begin{tabular}{llll}
\hline & 系数 & 标准差 & T检验 \\
\hline $\mathrm{C}$ & -2.395908 & 14.28957 & -0.16766 \\
$\mathrm{X} 1$ & 1.284696 & 1.495859 & 0.858836 \\
$\mathrm{X} 2$ & -13.15174 & 138.3244 & -0.095079 \\
$\mathrm{X} 3$ & -10.10987 & 2.883225 & $-3.506444 * *$ \\
$\mathrm{X} 5$ & 0.005342 & 0.007549 & 0.707621 \\
$\mathrm{X} 1 * \mathrm{X} 2$ & 2.113899 & 14.38003 & 0.147002 \\
$R^{2}$ & 0.219884 & & \\
\hline
\end{tabular}

注: *表示在 $10 \%$ 水平上显著, $* *$ 表示估计系数在 $5 \%$ 水平上显著, $* * *$ 表示估计系数在 $1 \%$ 水平上显著。

模型表明: 广告支出与企业绩效负相关, 但统计上不 显著, 这与假设 1 前半部分的说法不一致：广告支出与企 业绩效呈正相关。但是, 当企业规模越大、广告支出越多 时, 对零售企业绩效提升的作用越大, 统计上不显著。这 表明广告支出对企业绩效提升的作用会受到企业规模的 影响。这一点又验证了假设 1 的后半部分说法：企业规模 会影响广告支出与企业绩效的关系, 在大企业里, 二者的 关系会更强。

\section{3.2. 网络渠道效应考察}

本文采用如下模型来估计开通网络渠道对零售企业 绩效的影响, 以及广告支出与开通网络渠道交互作用对零 售企业绩效的影响:

$$
\begin{gathered}
Y_{i}=\beta_{0}+\beta_{1} X 1_{i}+\beta_{2} X 2_{i}+\beta_{3} X 3_{i}+\beta_{4} X 4_{i}+\beta_{5} X 5_{i}+ \\
\beta_{6} X 2_{i} X 4_{i}+\mu
\end{gathered}
$$

其中, $\mathrm{X} 4$ 为是否开通网络渠道, 为虚拟变量, 若企业 开通网络渠道, 则取值 1 , 否则取 0 。X $2 * X 4$ 表示广告支出 的存在对网络渠道与企业绩效关系的交互作用。如表 3 是 实证分析结果: 
表3 广告支出与开通网络渠道的交互作用。

\begin{tabular}{llll}
\hline & 系数 & 标准差 & $\mathrm{T}$ 检验 \\
\hline $\mathrm{C}$ & -3.477251 & 9.318861 & -0.373141 \\
$\mathrm{X} 1$ & 1.421070 & 1.026572 & $1.384287 *$ \\
$\mathrm{X} 2$ & 3.764722 & 7.171728 & 0.524939 \\
$\mathrm{X} 3$ & -9.998885 & 2.851833 & $-3.506126 * *$ \\
$\mathrm{X} 4$ & -0.761346 & 1.418043 & -0.536899 \\
$\mathrm{X} 5$ & 0.005475 & 0.007638 & 0.716757 \\
$\mathrm{X} 2 * \mathrm{X} 4$ & 8.531343 & 11.21144 & 0.760950 \\
$R^{2}$ & 0.226686 & & \\
\hline
\end{tabular}

注： *表示在 $10 \%$ 水平上显著, $* *$ 表示估计系数在 $5 \%$ 水平上显著, $*$ $* *$ 表示估计系数在 $1 \%$ 水平上显著。

模型使用全部的数据进行分析, 结果表明, 广告支出 对零售企业有正向作用, 但是不显著; 网络渠道开通对零 售企业的绩效有负向作用, 但是当企业有广告支出时, 就 对零售企业绩效有正向影响, 但是不显著。

就控制变量而言, 表 2 和表 3 的结果基本一致。在两个 模型中, 规模均对企业绩效有正向影响, 在模型一中不显 著, 在模型二中显著。规模作为常见的控制变量, 企业规 模越大, 经营绩效越好, 规模的扩大有利于扩大零售企业 市场占有率, 提高经营绩效。资本结构与企业绩效负相关, 且显著。一般来说, 资产负债率越高的企业, 公司管理层 越注重对经营风险的把控, 在一定程度上限制了企业的自 我发展。存货周转率对企业绩效有负向影响, 但是在两个 模型中均不显著。

\section{5. 结论与建议}

本文以 2015 年我国零售上市公司的数据实证检验了 企业规模对广告支出与企业绩效的关系与广告支出对开 通网络渠道与企业绩效关系的影响。在理论方面, 基于企 业实际情境, 讨论了针对不同规模企业广告支出对企业绩 效进行考察, 以及广告支出对是否开通网络渠道对企业绩 效的影响的调节。实证研究上，广告支出对企业绩效的影 响作用方向不确定, 与企业规模有关, 当企业规模越大, 则广告支出越多，对企业绩效的提升作用越大。

上述结论表明, 零售企业做广告不一定会有助于提升 其企业绩效，应该按照企业实际规模，做相应的调整。

企业开通网络渠道对零售企业绩效有负向作用, 但是 结合广告支出, 网络渠道的开通对企业绩效有一定的提升 作用, 虽然统计上结果不显著。现实情况是, 很多传统的 零售企业已经开通了网络渠道, 根据本文的整理, 2015 年中国零售企业百强中已有 37 家零售企业有自己专门的 购物网站, 部分网站制作的很精美, 但是事实上, 通过对 这些网站进行网站调研发现, 很多家零售商的网上的销售 量并不可观, 网站大多不为人知, 而消费者习惯的还是到 淘宝、京东等购物平台购物。各家购物网站趋同, 差异化 很小, 因此, 如果零售企业希望通过网络渠道提升企业绩 效，就应该有所不同，除了网站的制作外，提供差异化的 特色服务也是增强零售企业竞争力的关键。

本文的研究为零售企业决策提供了一定的参考价值, 零售企业不该随大流做广告, 而应该根据实际决策需要,
合理的开展广告活动。至于开通网络渠道, 更应该看清企 业自身需求, 不该盲目跟从。

\section{6. 局限性}

本文通过实证检验广告支出、网络渠道与零售业企业 绩效的关系, 尚存在很多不足, 首先, 在影响机制方面, 本文对广告支出、网络渠道对企业绩效的影响有实证研究, 但并未深究影响机制的作用机理, 这有待进一步研究。再 次, 所使用的控制变量未能将时间变化考虑在内, 这将在 以后的研究中加以改进。

\section{参考文献}

[1] Comanor, W. S. and Wilson, T. A., 1967, Advertising, Market Structure and Performance, Review of Economics and Statistics, 49 (11)

[2] BHAGWAT Y, DEBRUINE M. R\&D and advertising efficiencies in the pharmaceutical industry $[\mathrm{J}]$. International Journal of Applied Economics, 2011, $8(1): 55-65$

[3] Clarke. D. G. Economics Measurement of the Duration of Advertising Effect on Sale [J] Journal of Marketing Research, 1976(13) : 345-357

[4] Hirschey. M. and Weygandt. J, 1985, Amortization Policy for Advertising and Research and Development Expenditures, Journal of Accounting Research, 23(1): 326-335

[5] 杜渏, 㚞文英. 我国广告费用与销售额关系的实证研究 $[J]$ 山西农业大学学报, 2009. 8:153-158

６］许晖, 王宣喻. 广告投入与企业绩效——基于酿酒上市公司 的实证分析 $[J]$. 上海管理科学. 2013. 12 (1)

[7] 马艳艳, 张晓蕾, 逯雅雯. 研发支出、广告支出与企业经济 绩效一一基于中国不同制造业子行业的实证研究 $[\mathrm{J}]$. 大连 理工大学学报（社会科学版）, 2015, 36 (4)：30-36

[8］赵保国, 阙人超. 传统企业广告投入与企业绩效的非线性关 系研究——基于工业企业数据的门槛分析 $[\mathrm{J}]$. 北京邮电大 学学报（社会科学版）.2016, 18(4):92-100

[9] McGRATH C, ZELL. D. The future of innovation diffusion research and its implication for management: A conversation with Everett Rogers [J]. Jounal of Management Inquiry, 2001, 10(4) : 386-391

[10] 张林. 网络渠道在零售企业中的应用 $[\mathrm{J}]$. 现代商贸工业, 2008, 20 (10) : 350-351

[11] STEINFIELD C, ADELAAR T, LIU F. Click and mortar stratigies viewed from the Web: A content analysis of features illustrating intergration between retailers' online and offline presence $[\mathrm{J}]$. Electronic Markets, 2005, $15(3)$ : 199-212 
[12] 姜国政. 营销中的网络渠道与传统渠道 [J], 经济管理. 2005 (13) : 76-79

[13] BONNER J, KIN D, CAVUSGIL S T. Self-perceived stragic network identity and its effects on market performance in alliance relationships [J]. Journal of Business Research, 2005, 58(10): 1371-1380

[14] 邵家兵, 蒋飞, 宁蓓蓓. 网络渠道应用对中国零售业上市公 司绩效的影响 [J]. 重庆大学学报 (社会科学版) 2015, 21 (2) : 48-55

[15] 石平, 颜波, 石松. 不确定环境下网络渠道开通最优时机选 择 [J]. 系统工程理论与实践. 2015，35(4):872-881

[16] 贾建锋, 唐贵瑶, 李俊鹏, 王文娟, 单翔. 高管胜任特征与 战略导向的匹配对企业绩效的影响 [J]. 管理世界. 2015, (2) : 120-132

[17] 苏中锋, 孙燕. 不良竞争环境中管理创新和技术创新对企业 绩效的影响 $[\mathrm{J}]$. 科学学与科学技术管理. 2014, (6) : 110-118
[18] 吴超鹏, 唐菂. 知识产权保护执法力度、技术创新与企业绩 效——来自中国上市公司的证据 [J]. 经济研究. 2016, (11): 125-139

[19] 冯长利, 刘洪涛, 梅小敏. 供应链整合与企业绩效的关系研 究——基于Meta分析 [J]. 管理评论. 2016, 11:217-227

[20］曾德明, 苏亚. 国际化程度和企业绩效M型曲线关系研究 $[J]$. 科学学与科学技术管理. 2016, 4:25-34

[21] 李世英, 李延平, 蒋飞龙. 企业进入阻止行为与市场绩效关 系的实证研究——基于中国29个四位数制造业产业的面板 数据 $[\mathrm{J}]$. 上海经济研究, 2010 , (9) : $34-45$

[22] 孙维峰、黄祖辉, 广告支出、研发支出与企业绩效 [J]. 科 研管理. 2013, 34（2）:441-51

[23] 冯婉仪. 存货周转率对企业绩效的影响 $[\mathrm{J}]$. 现代经济信 息. 2012, 6:9 